This is the peer reviewed version of the following article: Sooniste, T., Granhag, P. A., Strömwall, L. A. and Vrij, A. (2014), Discriminating between true and false intent among small cells of suspects. Legal and Criminological Psychology. doi: 10.1111/lcrp.12063, which has been published in final form at http://onlinelibrary.wiley.com/doi/10.1111/lcrp.12063/full. This article may be used for non-commercial purposes in accordance with Wiley Terms and Conditions for Self-Archiving.

\title{
Discriminating between true and false intent among small cells of suspects
}

\author{
*Tuule Sooniste ${ }^{1}$, Pär Anders Granhag ${ }^{1,3}$, Leif A. Strömwall ${ }^{1}$ and Aldert Vrij ${ }^{2}$ \\ ${ }^{1}$ Department of Psychology, University of Gothenburg, Sweden \\ 2 \\ Department of Psychology, University of Portsmouth, UK \\ Norwegian Police University College, Norway
}

Word count (exc. figures/tables): 6671

\footnotetext{
*Requests for reprints should be addressed to Tuule Sooniste, University of Gothenburg, Psychology Department, P.O. Box 500, SE 40530 Gothenburg, Sweden, (e-mail: tuule.sooniste@psy.gu.se)

* Correspondence concerning this article should be addressed to: Tuule Sooniste, University of Gothenburg, Psychology Department, P.O. Box 500, SE 40530 Gothenburg, Sweden, or via email: tuule.sooniste@ psy.gu.se. This work is funded by High-Value Detainee Interrogation Group contract (J-FBI-10-009) awarded to subcontract Pär Anders Granhag, University of Gothenburg, Department of Psychology, through the University of Texas at El Paso. Statements of fact, opinion and analysis in the paper are those of the authors and do not reflect the official policy or position of the FBI or the U.S. Government.
} 


\begin{abstract}
Purpose. Despite high potential value for real-life situations, detecting true and false intentions by groups of suspects has not been previously investigated.

Method. The experimental study had a set-up in which participants $(N=232)$, half in dyads and half in quartets, planned for either a mock crime or a non-criminal event. In structured individual interviews, all participants were asked one set of questions targeting their intentions (anticipated questions) and one set of questions targeting the planning phase of the intentions (unanticipated questions). We scored the level of detail and consistency in participants' interview responses.
\end{abstract}

Results. As predicted, questions on the planning phase were perceived as unanticipated and difficult to answer by both liars and truth-tellers. Truth-tellers' answers to the question on intent were perceived as more detailed compared to the liars. Cells of truth tellers and liars achieved an equally high within-group consistency for their answers to the questions on the stated intentions, whereas cells of truth tellers achieved a higher within-group consistency for the answers to the questions on the planning phase. Finally, truth-tellers' descriptions of their intentions contained more information related to how to attain the stated goal, whereas liars gave more information related to why it was necessary to attain the stated goal.

Conclusions. Asking anticipated and unanticipated questions can be a successful way of eliciting cues to true and false intentions among small cells of suspects.

Keywords: true intentions, false intentions, cells of suspects, goal-directed behavior, consistency 


\section{Discriminating Between True and False Intent among Small Cells of Suspects}

With over thirty years of systematic research the detection of deception marks one of the largest sub-genres of forensic psychology (Granhag \& Strömwall, 2004; Vrij 2008). Despite this, notable omissions in this field are evident. The current experiment addresses two such understudied areas: the study of true and false intentions and the study of small cells of suspects.

The applied value of examining true and false intentions is immense. History is rife with situations, from terrorist actions to school shootings, where the eventual perpetrator was not only known to the police but had in fact been interviewed by them prior to the act (e.g., Matti Juhani Saari, Finland, 2008). In addition, many crimes are planned and/or performed by groups rather than individuals (van Mastrigt \& Farrington 2009). Modern terrorism provides a salient example of the prevalence of group criminal activities. Although single terrorists may receive a disproportionate amount of media attention (e.g., the Anders Behring Breivik massacre, Norway, 2011), most devastating attacks are carried out by groups (e.g., September $11^{\text {th }}$ attacks 2001, Madrid train bombings 2004). Indeed, Crenshaw (1990; 2000) asserts that terrorism is primarily a group activity.

A handful of studies exist on the topic of true and false intentions (e.g., Granhag \& Knieps, 2011; Vrij, Leal, Mann, \& Granhag 2010). These studies define intentions as an individual's mental state preceding his or her corresponding action (see Malle, Moses \& Baldwin, 2003). Typically, the definition is further delineated to refer to planned acts to be performed in the near future. The existing studies on true and false intentions have provided important ground laying work. The first set of studies (Vrij et al., 2010; Vrij, Granhag, Mann, \& Leal, 2011) sought to gauge how proficient people are at discriminating between true and false intentions, based solely on simple interactions with the truth tellers and liars. Results 
showed a discrimination accuracy of approximately 70\%. A more theory-driven approach sought to increase differences in truth tellers and liars by examining possible cognitive discrepancies (e.g., propensity for engaging in episodic future thought; Granhag \& Knieps, 2011).

A recent approach is characterized by strategic interviewing methods. In their metaanalysis, Hartwig and Bond (2011) concluded that an efficient way of improving lie detection techniques is to increase the (otherwise weak) behavioral differences between truth tellers and liars. This is exactly what strategic interviewing attempts to achieve (see also Vrij \& Granhag, 2012). So far, two different types of strategic interview methods have been employed on intentions: the strategic use of evidence technique (Clemens, Granhag \& Strömwall, 2011), and the unanticipated questions approach (Sooniste, Granhag, Knieps, \& Vrij, 2013). The unanticipated questions approach is used in the present experiment and posits that liars and truth tellers will differ in their ability to answer unexpected questions during an interview. Research has shown that liars are often as capable as truth tellers at answering typical questions, as they will have planned and prepared for these questions (Vrij et al., 2009). However, for unanticipated questions, liars' competence at answering may be impaired, as they, unlike truth tellers, cannot rely on simple recall or on prepared answers (Sooniste et al., 2013). Differently put, liars do not seem to prepare for questions on the planning of their stated intentions. In addition, liars may have to monitor their fabrication of the answer to make sure it is perceived as plausible, and that what is stated adheres to what the interviewer might know, or might find out (Vrij et al., 2011a). Therefore, the use of the 'unanticipated question' tactic may impose more cognitive load on liars than on truth-tellers. The unanticipated questions approach has been shown to be effective in enhancing differences between statements expressing true and statements expressing false intentions. Sooniste, et al. (2013), compared truth tellers' and liars' responses for both anticipated and unanticipated 
questions. The anticipated questions directly concerned what the participants intended to do, whereas the unanticipated questions concerned the phase where the stated intentions were planned. The truth-tellers provided longer and more detailed answers in comparison to the liars when answering to the unanticipated questions.

The current study extends the work by Sooniste et al. (2013) by applying the unanticipated questions technique to groups of suspects rather than individuals. Groups of suspects have only raraly been studied in deception detection research (see Driskell, Salas, \& Driskell, 2012; Strömwall, Granhag, \& Jonsson, 2003; Vrij et al., 2009, 2012), and never in research on true and false intentions. Furthermore, research indicates that asking unanticipated questions may be particularly suited for groups of suspects. Granhag, Strömwall and Jonsson (2003) found that pairs of liars jointly planned fabricated stories in order to minimize the risk of their statements being inconsistent with each other. Due to this planning the between suspect consistency level of liars was comparable to that of truth tellers. However, if groups of liars were asked questions which they did not plan for it might be assumed that they would be likely to reach lower level of consistency, and this level is expected to decrease further as the number of members in the group is increasing. Furthermore, when considering the reconstructive nature of human memory, truthful members of the same group can differ in what they remember. This can cause similar effect to the liars, that is, within group consistency decreasing as the size of the group is increasing. Although, groups of liars who have prepared ready-made answers to the anticipated questions may very well achieve as high consistency in their answers as will truth-teller of the same group size. This issue was addressed in a study by Vrij and colleagues (2009). As predicted, liars performed similarly to truth tellers with regards to within group consistency for anticipated questions. However, for unanticipated questions liars' statements were considerably more inconsistent than their honest counterparts. Based on the within-group consistency for unanticipated questions liars 
and truth tellers were accurately classified in over $80 \%$ of the cases. The current study differs from that of Vrij et al. (2009) in four important aspects. First, it addresses intentions rather than past events. Second, in the study by Vrij et al (2009) the unanticipated questions were restricted to questions on spatial and temporal aspects, in the current study the unanticipated questions target the planning phase in full. Third, the current study compares the influence of group size on the dependent variables number of words, level of detail and consistency for both groups of two and groups of four. Fourth, the present study draws on established research findings from the field of social cognition, particularly the theory of implementation intentions.

It is argued that implementation intentions are if-then plans, and that such plans connect the opportunity to act with cognitive and behavioral activities that will be effective in accomplishing one's goal (Sheeran, Milne, Webb \& Gollwitzer, 2005). A crucial distinction is made between so-called goal intentions, which specify what someone wants to do (e.g., "I intend to go to Italy"), and implementation intentions, which specify the behavior that someone will perform in the service of goal achievement (i.e., "If it is too expensive to fly, I will take the train"). In essence, an implementation intention specifies the when, where and how of what someone will do. Importantly, it has been shown that when people have no intention of pursuing a certain goal they are unlikely to form an intention implementation that spells out adequately how the goal will be pursued (Sheeran et al., 2005). Translated to the current context, it is expected that truth-tellers' (more than liars') answers will be characterized by information pertaining to how the stated intentions will be reached.

In contrast, we can assume that liars form implementation intention but that it will be directed towards executing and hiding the criminal intention. Liars are not concerned about how to attain the goal that they state in the interview; this is a false intention, which only serves the purpose to mask their real intentions (the criminal acts). As liars are more occupied 
with convincing the interrogator about their truthfulness, they might focus more on why they need to execute the stated intention. Recent empirical work on liars' counter-interrogations strategies reveals that when lying suspects anticipate questions on intentions (Clemens, Granhag \& Strömwall, 2012), and when they have partners in crime (Granhag, Mac Giolla, Strömwall \& Rangmar, 2013), they will (a) prepare ready-made answers to the expected questions, and (b) these ready-made answers will be geared toward why they will do what they (falsely) claim that they will do. Furthermore, one might assume that liars, who generally do not take their credibility for granted and who might anticipate that their stated intentions will be questioned, may feel a relatively stronger need to motivate why the stated goal is necessary to reach. In sum, based on previous work we can expect those who state true intentions (truth-tellers) to address how the intention should be reached, and those who state false intentions (liars) to address why the intention is necessary to reach.

\section{The Present Study}

The present study is based on an experimental set up introduced by Granhag and Knieps (2011), but advances previous research on several accounts. First, the experimental set-up is refined to fit the aim of studying small cells of suspects (dyads and quartets). Second, we tapped within group consistency, both with respect to the answers given to the anticipated questions (the intentions) and to the unanticipated questions (the planning-phase). Third, we utilized the theory of implementation intentions (Sheeran et al, 2005), and examined to what extent the predictions following from this theory can be used to detect differences between statements expressing true and false intentions. The study involved half of the dyads and half of the quartets to plan for a non-criminal event, whereas the remaining dyads and quartets planned for a mock-crime. All group members were intercepted before having the chance to carry out their planned activities, and they were interviewed individually. Those having planned a non-criminal act were instructed to tell the truth in a forthcoming interview, 
whereas those having planned a mock-criminal act were instructed to conceal their criminal intentions by telling a cover story (i.e., they were asked to lie). The cover-story used by the lying participants was structurally similar to the non-criminal intentions expressed by the truth-telling participants. That is, we created a situation in which all participants expressed rather similar intentions (i.e., that they were about to go to a specific mall to shop for a special lunch), but for half of the participants this was a lie and for the remaining half it was the truth.

We predicted that both liars and truth-tellers would perceive the questions targeting their intentions as more anticipated compared to the questions targeting the planning of their stated intentions (Prediction 1). In a similar vein, we predicted that both liars and truth-tellers would perceive the questions on their intentions as less cognitively demanding to answer, compared to the questions asked on the planning-phase (Prediction 2a). To qualify this further, we predicted an interaction effect, showing that lying (vs. truth-telling) suspects would perceive the unanticipated questions as more difficult to answer, whereas no such difference was predicted for the anticipated questions (Prediction 2b). Furthermore, we predicted that truthtellers would provide more detailed answers to the unanticipated questions than liars (Predictions 3).

Regarding within-group consistency, for the unanticipated questions we predicted cells of truth-tellers would produce more consistent answers than liars (Prediction 4a). In addition, based on the reconstructive nature of memory (e.g., Baddeley, 1990) we predicted that dyads would produce more consistent answers than quartets, and this would hold true for both liars and truth-tellers (Prediction 4b).

Finally, based on both theoretical (e.g., Gollwitzer, 1990) and empirical research (e.g., Sheeran et al, 2005) on goal directed behavior and implementation intentions, we predicted that the truth-tellers' answers to the questions on intentions would be more characterized by information relating to how to attain the stated goal (Prediction 5a), whereas liars' answers to 
questions on their intentions would be more characterized by information related to why the stated goal have to be pursued (Prediction 5b).

\section{Method}

\section{Participants and Design}

In all, 232 individuals participated in the experiment, mainly undergraduate students (Mean age $=28.04, S D=8.89) ; 69$ were men and 160 women, 3 participants chose not to report their gender. As compensation they received a movie ticket and a lottery ticket (total value approximately $\$ 25$ ). We employed a $2 \times 2$ between-group experimental design, in which participants were randomly allocated to one of two veracity conditions; a true intention condition $(n=116)$, in which a non-criminal activity was planned, and a false intention condition $(n=116)$, in which a criminal activity was planned. Each veracity condition was further divided into groups, either four persons (quartets) or groups of two persons (dyads). This resulted in 19 quartets and 20 dyads in each veracity condition. Groups that contained individuals previously knowing each other were evenly allocated to the veracity and group size conditions. Before the experiment started all participants were informed that they could withdraw from the experiment at any time.

\section{Procedure}

Planning phase. Participants in both veracity conditions were given 20 minutes to plan. The non-criminal activity was to go to a shopping mall in order to shop for a special lunch. During the planning phase all participants were provided with maps of the shopping mall ("Nordstan", which is one of Northern Europe's largest shopping malls), a list of relevant web pages and access to the internet. In addition, the liars received detailed photos of the four different shops and the shelves from which they had to collect the four items. In order to motivate the participants to plan carefully the execution of the task was limited by two explicit constraints; they were instructed that this was their only opportunity to carry out the 
tasks, and that they had limited time at their disposal. In addition, several initiatives were taken in order to have all participants believe that they were actually going to execute their planned actions (e.g., providing them with bus tickets).

Truth-tellers were asked to plan and prepare a typical Swedish lunch for two exchange students within a time limit. Preparation included going to a shopping mall to buy the required goods. The planning was further motivated by saying that they are participating in a competition (together with other groups) for making the best lunch. Liars were asked to imagine that they were devoted animal activists and together with other activists had accepted to carry out a secret mission to stop harmful experiments on animals. Their mission was part of a larger operation where the aim was to crash the computer system of the "Concrete Pharmaceutical Company", an organization which conducts animal testing. More specifically, liars were asked to collect four items needed to execute the criminal act from the main shopping mall in Gothenburg (mock-criminal activity). These items were: (a) a memory-stick containing illegal information, (b) an envelope containing a key, (c) a paper with passwords and usernames, and (d) a map showing the way to a specific office. Importantly, liars were also asked to plan a cover story masking their criminal intention. They were provided with the frame for the cover story, which was structurally similar to the activity truth-tellers had to plan for (i.e., a typical Swedish lunch for two exchange students). This cover story was to be used if intercepted.

Interception. All participants were intercepted before executing their planned actions. They were then handed a sheet of instructions asking them to imagine that they had faced a security check at the entrance of the shopping mall, and when trying to pass this security check they had been selected for further questioning. Furthermore, they were told that they were brought to a nearby interviewing room, and that they were to wait in this room to be interviewed. The participants who had planned for the illegal activities were asked to use their 
cover story in order to avoid detection. The participants who had planned for the non-illegal activities were asked to tell the truth about their intentions.

Interviews. All participants were interviewed individually according to a structured interview protocol. Participants were interviewed once. In the quartets, two interviewers were used and two participants were interviewed simultaneously but in separate rooms. Participants could not hear each other's answers. The other two participants were kept waiting in different rooms. In the dyads, one interviewer was used and participants were interviewed one after another. We used a total of five trained interviewers. All interviewers were blind to the participants' truth status and to the experimental hypotheses. All participants received questions on their intentions and on the planning phase. In the first part of the interview the suspects were asked the following five questions on their intentions: (1) "I want you to tell me what you intend to do in Nordstan. Please tell me about each and every step, and try to be as detailed as possible?"; (2) "How long do you intend to stay in Nordstan?"; (3) "Which shop do you intend to visit first?", and (4) "Which other shops do you intend to visit in Nordstan?"; (5) "Which entrance did you intend to use to enter and exit Nordstan". In the second part of the interview the participants were asked the following six questions about their planning of their stated intentions: (1) "I want you to think back to when you planned your errand. I want you to tell me about your planning, and I want you to be as detailed as possible?"; (2) "What was the main goal of your planning?"; (3) "I want you to tell me about the order in which you planned your errand?"; (4) "What was the final thing you planned?"; (5) "What was the easiest part of your planning?", and (6) "What was the most difficult part of your planning?". However, for the current paper only the answers given to the first question is of relevance.

Post-interview questionnaire. After the interview each participant was asked to fill out a post-interview questionnaire. For lying suspects, this questionnaire started with a separate section making it utterly clear that the role-playing part of the study was over, and that all 
questions should be answered in a truthful manner. We asked participants to evaluate their experiences of the planning phase. The questionnaire contained questions such as how difficult they perceived, how satisfied they were with the planning phase and how satisfied they were with the time allocated. In addition, each participant was given a copy of the interview protocol, and for each question he or she was asked to rate on a 7-point Likert scale (a) how anticipated that particular question was and (b) how difficult that question was. These 11 items were averaged to create a single measure for anticipation/intention (Cronbach's $\alpha=$ .85), cognitive complexity/intention $(\alpha=.73)$, anticipation/planning $(\alpha=.91)$ and cognitive complexity/planning $(\alpha=.88)$.

\section{Ratings}

Level of detail. Two assistants, blind to the participants' veracity status, rated the level of detail of each individual answer on a 7-point Likert scale both on the main question on intent ("I want you to tell me what you intend to do in Nordstan. Please tell me about each and every step - and try to be as detailed as possible?") and planning (“Now, I want you to think back to when you planned your errand. I want you to tell me about your planning, and I want you to be as detailed as possible?"). The scores ranged from (1) very low in terms of detail to (7) very high in terms of detail. Both assistants rated all statements. The Intra-class Correlation Coefficient (ICC) was .86, 95\% CI [0.82, 0.89] for details/planning and .90, 95\% CI [0.87, 0.92] for details/intentions, showing good inter-rated reliabilities. In order to test the group effect, we calculated mean value for each group.

Consistency. Two research assistants, blind to the participants' veracity status, rated the global consistency of the answers given by the group (Dyads and Quartets) on a 7-point Likert scale both on the main question on intent and planning. The scores ranged from (1) very low in terms of consistency to (7) very high in terms of consistency. One person rated all 
statements and the other rated $40 \%$ of the statements. The ICC was $.90,95 \%$ CI $[0.79,0.95]$ for consistency/planning and $.78,95 \% \mathrm{CI}[0.52,0.90]$ consistency/intention.

Content-based analyses. Two research assistants, blind to the participants' veracity status, rated to which extent they perceived each individual answer to be characterized by information that related to the questions why and how on a 7-point Likert scale both on the main question on intent and planning. The scores ranged from (1) very low in terms of information related to the questions how/why to (7) very high in terms of information related to the questions how/why. Both coders coded $100 \%$ of the statements. The ICC was .89, 95\% CI $[0.92,0.95]$ for information why/intention and .86, 95\% CI [0.82, 0.89] information how/intention.

\section{Results}

\section{Manipulation Check and Preliminary Analyses}

Veracity. The liars $(M=4.79, S D=1.63)$ rated their degree of lying significantly higher than truth-tellers $(M=1.82, S D=1.32), t(229)=15.18, p<.001, d=2.00$. This indicates that the participants complied with our instruction to lie or tell the truth. In addition, we found that liars $(M=5.88, S D=0.70)$ were significantly more motivated to be believed by the interviewer than truth-tellers $(M=5.45, S D=1.51), t(229)=2.59, p=.01, d=0.37$. Critically, the absolute values (close to 6 on a 7-point scale) indicate that both lying and truthtelling suspects were highly motivated.

Perceptions of the planning phase. As the planning phase was at the heart of the study, we asked our participants a number of different questions relating to this phase. First, truthtellers $(M=3.36, S D=1.47)$ found it less difficult to plan for their future events than liars $(M$ $=4.13, S D=1.59) t(229)=3.87, p<.001, d=0.50$. Furthermore, liars $(M=4.06, S D=1.48)$ were less satisfied with the planning phase than truth-tellers $(M=5.23, S D=1.31), t(229)=$ $6.40, p<.001, d=0.84$. Finally, liars $(M=4.65, S D=1.77)$ were less satisfied with the time 
allocated to the planning-phase than truth-tellers $(M=5.37, S D=1.80), t(229)=-3.10, p<$ $.01, d=0.40$. However, the absolute values indicate that both groups of suspects perceived the time allocated for planning as sufficient.

\section{Anticipation and Cognitive Complexity}

Anticipation. A two-way ANOVA with Veracity as a between-subject factor and Type of Question (questions on intent vs. questions on planning) as a within-subjects factor, showed a main effect for Type of Question. The questions about the planning phase $(M=4.64, S D=$ 0.78) were perceived as significantly more unanticipated than the questions about the intentions $(M=3.51, S D=0.76), F(1,230)=224.19, p<.001, \eta^{2}=.49$, supporting Prediction 1. We also found a main effect of Veracity: liars $(M=4.34, S D=.09)$ perceived both types of questions as more unanticipated than truth-tellers $(M=3.82, S D=1.10) F(1,230)=15.09, p<$ $.001, \eta^{2}=.06$. The interaction was not significant $F(1,230)=0.83, p<.36, \eta^{2}=.004$.

Cognitive complexity. A two-way ANOVA with Veracity as a between-subject factor and Type of Question (questions on intent vs. questions on planning) as a within-subjects factor showed a significant main effect for Type of Question. The questions about the planning-phase $(M=3.30, S D=1.14)$ were perceived as significantly more difficult to answer than the questions about the intentions $(M=2.69, S D=0.97), F(1,230)=91.38, p<.001, \eta^{2}=$ .28. This supports Prediction 2a. We also found a significant main effect for Veracity, $F(1,230)=23.44, p<.001, \eta^{2}=.09$. Liars $(M=3.29, S D=0.97)$ perceived the questions as more difficult to answer than did truth tellers $(M=2.72, S D=0.82)$. The Type of Question $\times$ Veracity interaction effect was not significant, $F(1,230)=2.55, p=.11, \eta^{2}=.01$. Thus, we did not find support for Prediction $2 b$.

\section{Level of Detail}

Intentions. A two-way independent ANOVA with Veracity (truth-tellers vs. liars) and Group size (dyads vs. quartets) as between-subject factors and level of detail as dependent 
variable showed a main effect for Veracity. Liars' answers $(M=3.00, S D=1.09)$ to the main question on the intent were perceived as significantly less detailed than truth-tellers' answers $(M=3.78, S D=1.09), F(1,74)=9.96, p=.002, \eta^{2}=.12$. The main effect for Group size was not significant; the dyads $(M=3.55, S D=1.36)$ and the quartets $(M=3.22, S D=0.86)$ did not differ in terms of the level of detail, $F(1,74)=1.82, p=.18, \eta^{2}=.02$. The Veracity $\times$ Group size interaction was not significant either, $F(1,74)=0.27, p=.60, \eta^{2}=.004$.

The planning phase. A two-way independent ANOVA with Veracity (truth-tellers vs. liars) and Group size (dyads vs. quartets) as between-subject factors and level of detail as dependent variable showed a main effect for Veracity. Liars' answers $(M=2.37, S D=0.97)$ to the main question on the planning phase were perceived as less detailed than truth-tellers' answers $(M=4.12, S D=1.24), F(1,74)=50.60, p<.001, \eta^{2}=.41$, supporting Prediction 3 . Furthermore, we found a main effect for Group size. Answers given by the individuals in the quartets $(M=2.92, S D=1.22)$ were perceived to be less detailed than answers given by individuals in the dyads $(M=3.55, S D=1.52), F(1,74)=6.59, p=.01, \eta^{2}=.08$. The Veracity $\times$ Group size interaction was not significant, $F(1,74)=0.001, p=.98, \eta^{2}=.00$.

\section{Consistency}

Intentions. A two-way independent ANOVA with Veracity (truth-tellers vs. liars) and Group size (dyads vs. quartets) as between-subject factors and consistency as dependent variable showed a main effect for Group size. As predicted, quartets' answers $(M=1.92, S D$ $=0.94)$ to the main question on intent were perceived as less consistent than dyads' answers $(M=3.17, S D=1.43), F(1,74)=20.23, p<.001, \eta^{2}=.21$. The main effect for Veracity was not significant; cells of liars $(M=2.53, S D=1.30)$ and cells of truth-tellers $(M=2.62, S D=$ 1.44) did not differ in terms of consistency, $F(1,74)=0.15, p=.70, \eta^{2}=.002$. The Veracity $\times$ Group size interaction was not significant, $F(1,74)=0.01, p=.94, \eta^{2}=.00$. 
The planning phase. A two-way independent ANOVA with Veracity and Group size as between-subject factors, showed a main effect for Veracity. Specifically, liars' answers $(M=$ $1.26, S D=0.72$ ) to the main question on the planning phase were perceived as significantly less consistent than the truth-tellers' answers $(M=1.69, S D=1.03), F(1,74)=5.68, p<.02$, $\eta^{2}=.07$, supporting Prediction 4a. Furthermore, the main effect for Group size showed the expected pattern (Prediction 4b); answers given by the quartets $(M=1.85, S D=1.12)$ were perceived to be less consistent compared to the answers given by the dyads $(M=1.08, S D=$ 0.27), $F(1,74)=18.35, p<.001, \eta^{2}=.20$. The Veracity $\times$ Group size interaction was not significant, $F(1,74)=2.27, p=.14, \eta^{2}=.03$.

\section{Content-based Analysis: Goal-directed Behavior}

A one-way ANOVA showed that truth-tellers' answers to the main question about their intentions were significantly more characterized by the information related to the question how $(M=5.30, S D=1.29)$ than the liars' answers to the same question $(M=4.27, S D=$ $1.27), F(1,234)=38.24, p<.001, \eta^{2}=.14$. This supports Prediction 5a. Furthermore, a oneway ANOVA showed that liars' answers to the main question about their intentions were significantly more characterized by the information related to the question why $(M=2.92, S D$ $=1.19)$ than the truth-tellers' answers to the same question $(M=1.90, S D=0.95), F(1,234)=$ $56.41, p<.001, \eta^{2}=.20$, supporting Prediction 5b.

\section{Discussion}

We examined differences between truth-telling and lying suspects with regard to several aspects of their answers to questions about both intentions and planning of an event. Overall, we found ample support for our predictions: when having planned a criminal event, people answer questions differently than when planning a non-criminal event. These differences may be used to differentiate those lying and those telling the truth in real-life settings such as police interviews or border controls. The present study extended the previous research on two 
important accounts; we examined the effect of multiple suspects on the level of consistency and we tied the analysis to the theory of implementation intentions.

The most important results were that liars and truth-tellers differed on key aspects. The truth-tellers' answers to the unanticipated questions (i.e., the planning phase) were perceived as significantly more consistent than the liars' answers to the same questions. Furthermore, answers to the anticipated questions (i.e., the stated intentions) given by the cells of liars and cells of truth-tellers were perceived as equally consistent. Answers given by the quartets were perceived to be less consistent than the answers given by the dyads for both the planning phase and intention questions. The liars' (vs. truth tellers') answers to the question on their stated intentions were characterized more by information related to why to attain the stated goal, whereas truth-tellers focused on telling how the stated goal would be pursued.

In line with the assumptions, liars' (vs. truth-tellers) gave less detailed answers to the questions on the planning phase. That is, according to the unanticipated questions approach truth-tellers are in better position at answering the questions on the planning phase which results in more detailed answers compared to liars. Unexpectedly we also found that liars' (vs. truth-tellers) gave less detailed answers to the questions on their intentions. This might be explained by recent study showing that a common strategy among small cells of guilty suspects in preparing for an upcoming interview is to be restrictive with respect to the information that they would tell during the interview (Granhag et al, 2012).

Research has shown that, if the situation allows, observers assessing the credibility of a set of statements tend to rely on consistency as a cue to deception and truth (e.g., Strömwall, Granhag \& Jonsson, 2003). In essence, cells of truth-tellers and cells of liars showed the same level of consistency when answering questions about their intentions, whereas cells of truthtellers (vs. cells of liars) were significantly more consistent when answering questions about the planning phase. The latter part of the finding is in line with recent study by Mac Giolla 
and Granhag (2013) showing same results on triads. Furthermore, these findings are in line with the assumptions that liars had agreed upon what to say if faced with questions on their intentions (anticipated), but that they had not discussed what to say if faced with questions on the planning of the stated future event (unanticipated). In addition, we found that dyads achieved a higher degree of consistency than quartets, and this held true across both domains of questions (intentions and planning). This is in line with our prediction and is not difficult to explain considering what is known about the reconstructive nature of human memory (e.g., Baddeley, 1990). That is, when reconstructing the past, members of the same group will - to some extent - differ with respect to the information (details) they remember and tell. Therefore, as the size of the group increases the number of potential comparisons that can be made increases, which in turn, should result in lower consistency between statements (i.e., a reduction in within-group consistency). This finding may come across as trivial, but it has an important practical implication: One should be careful in discrediting a group of individuals on the basis of any degree of within-group inconsistency; groups of truth-tellers do also show some degree of inconsistency.

Furthermore, we tied our analyses to research on implementation intentions. Consistent with the work by Gollwitzer and colleagues (e.g., Gollwitzer, 1990, Sheeran et al. 2005), we found that truth-tellers' answers to the questions on intentions were more characterized by information related to how the stated goal will be pursued. In contrast, liars' answers to the questions on their intentions were more characterized by information related to why the stated goal will be pursued. This result is in line with recent empirical studies showing that when lying suspects anticipate questions on intentions (Clemens et al., 2012), they will prepare ready-made answers and these ready-made answers are argued to be geared toward why they will do what they (falsely) claim that they will do. That is, liars may feel stronger need to persuade the interrogator in their truthfulness and therefore focus on producing convincing 
answers to the question why they need to execute their stated intentions. Importantly, both the how and the why findings are vital. Combined they (a) provide a new theoretical dimension to the psycho-legal work emerging within this domain, (b) extend Gollwitzer's work by showing that the trademarks of those less committed to pursue a specific goal can also be found among those who are lying about pursuing a specific goal, and (c) show that a theory-driven content analysis of the answers given to questions on intentions might help to discriminate between true and false intentions.

In connection to the above, we would like to acknowledge two issues. First, both deceptive and truthful statements contained information related to how and information related to why. Hence, from finding information of either kind in a statement, one cannot decide on the statement's veracity. Second, implementation intentions specifies the when, where and how of what one will do, but for the current study we only focused on the how aspect. The reason for this was that the liars' cover-story was clearly situated in time and place, and this context was the same for truth-tellers. Therefore we had no reason to expect differences between liars and truth-tellers with respect to when and where. However, future studies in this domain, using a set-up where the when and where are up to the liar to decide, might profit from an analysis in which all aspects of implementation intentions are considered.

Importantly, the questions on the intention were perceived as more anticipated by both truth-tellers and liars compared to the questions on the planning of their stated intentions. For the present study this finding is critical; had the two sets of questions been perceived as equally anticipated, the rest of our reasoning had been left short. Furthermore, both liars and truth-tellers perceived the questions on the planning-phase as more difficult to answer compared to the questions on the intentions. Similar findings have been found in previous studies (e.g., Mac Giolla \& Granhag 2013, Sooniste et al 2013, Warmelink et al 2012). 
As the planning phase is at the heart of the current approach we asked our participants a number of questions relating to this phase. We found that truth-telling suspects perceived it as less difficult to plan for their future events compared to lying suspects. In addition, lying suspects indicated that they were more satisfied with the planning-phase, and less satisfied with the time allocated to the planning-phase compared to the truth-tellers. It should be noted that the absolute values indicated that both liars and truth-tellers perceived the time allocated for planning as sufficient. In sum, we do not believe that the results of the current study could be explained by liars having received too little time to plan.

\section{Limitations}

There are limitations to our approach and findings. Perhaps the most striking is that a majority of our participants were university students, which raises the question of whether our findings can be generalized to real-life settings. We think it can. Our approach takes into account liars' and truth-tellers' counter-interrogation strategies (Granhag \& Hartwig, 2008). The counterinterrogation strategy most relevant for the current study is that liars will prepare ready-made answers to anticipated questions, and that their aim is to make sure to convince the interviewer that the stated goal is necessary to attain. Importantly, these assumptions are not just derived from past research (e.g., Clemens et al, 2012; Granhag et al, 2013), but are also supported by so-called resistance manuals (e.g., The Manchester manual) and other texts written by terrorists for terrorists (e.g., the manifest written by Anders Behring Breivik). In essence, the outcome of the current study fits neatly with how terrorists are advised to behave when being questioned. Hence, we believe that the current findings do apply to real-life settings. We even speculate that some of the differences may be magnified in real-life settings, as real criminals will be much more motivated to stick to the rehearsed counterinterrogation strategies and hide their real intentions compared to our mock-suspects.

\section{Implications and Conclusions}


With respect to the practical implications, we believe that any interview protocol that aims at discriminating true and false intentions should target both the intentions as such, and the phase in which the stated intentions were planned. If keeping in mind that, cells of suspects will prepare what to say, one should be cautious looking only the consistency of the answers given to the anticipated questions. One should instead concentrate on the answers given to the unanticipated questions and compare it with the answers to anticipated questions. In the same vein, if keeping in mind that truth-tellers will struggle with how to attain the stated goal, whereas liars will struggle with convincing the interviewer why the stated goal is necessary to attain, one ought not pay too much attention to the richness of the answer but rather concentrate on specific aspects of the content. Our paper shows that in order to decide whether a stated intention is true or false one need to know both which questions to ask and how to analyze the answers given.

The current study is to be placed within the new wave of deception detection research characterized by asking questions strategically in order to elicit cues to deception and truth (Vrij \& Granhag, 2012). Specifically, we would like to argue that our study represents a rather successful attempt at eliciting cues to true and false intentions among small cells of suspects. Our assumptions found strong support as truth-tellers' and liars' answers to the questions targeting the unanticipated question (planning phase) differed in terms of level of detail and consistency to a greater extent in contrast to the answers targeting the anticipated questions (stated intention). That is, asking a small group of suspects about their intentions only will probably elicit very few and faint cues to deception, whereas asking about the planning preceding the stated intention will elicit several and rather strong cues to deception.

Furthermore, the current paper is the first to use the theory of implementation intentions to predict differences between true and false intentions. This successful attempt does not only add theoretical strength to the current research, it also demonstrates that it is possible to 
differentiate between liars and truth-tellers by analyzing the answers given to questions targeting their intentions. However, these differences might go undetected if limiting the analysis to the more traditional measures used in deception detection research. Instead there is a need for a theory-driven approach, which will illuminate differences with respect to liars' and truth-tellers' goal-directed behavior, and how these differences are manifested in how they talk about goal pursuit. We foresee that this paper will open doors for future work in which the detection of true and false intent will be guided by established theory on goaldirected behavior. 


\section{References}

Baddeley, A. (1990). Human memory: Theory and practice. Hove, UK: Lawrence Erlbaum.

Clemens, F., Granhag, P.A., \& Strömwall, L.A. (2011). Eliciting cues to false intent: A new application of strategic interviewing. Law and Human Behavior, 35, 512-522. DOI: 10.1007/s10979-010-9258-9

Clemens, F., Granhag, P.A., \& Strömwall, L.A. (2013). Suspects' counter-interrogation strategies when anticipating questions on intentions. Journal of Investigative Psychology and Offender Profiling, 10, 125-138

Crenshaw, M. (1990). Questions to be answered, research to be done, knowledge to be applied. In W. Reich (Ed.), Origins of terrorism: Psychologies, ideologies, theologies, states of mind (pp. 247-260). Cambridge: Cambridge University Press.

Crenshaw, M. (2000). The psychology of terrorism: An agenda for the 21st century. Political Psychology, 21, 405-420. DOI: 10.1111/0162-895X.00195

Driskell, J. E., Salas, E., \& Driskell, T. (2012). Social indicators of deception. Human Factors, 54, 577-588.

Gollwitzer, P.M. (1990). Action phases and mindsets. In E.T. Higgins \& J.R.M. Sorrentino (Eds). The handbook of motivation and cognition, (pp. 53-92). Vol. 2, New York: Guilford Press.

Granhag, P.A., \& Hartwig, M. (2008). A new theoretical perspective on deception detection: On the psychology of instrumental mind reading. Psychology, Crime \& Law, 14, 189-200. DOI: $10.1080 / 10683160701645181$

Granhag, P.A. \& Knieps, M. (2011). Episodic future thought: Illuminating the trademarks of forming true and false intentions. Applied Cognitive Psychology, 25, 274-280. DOI: 10.1002/acp.1674 
Granhag, P.A., Mac Giolla, E., Strömwall, L.A. \& Rangmar, J. (2013). Counter-interrogation strategies among small cells of suspects. Psychiatry, Psychology \& Law. DOI: $10.1080 / 13218719.2012 .729021$

Granhag, P.A. \& Strömwall, L.A. (Eds).(2004). The detection of deception in forensic contexts. Cambridge: Cambridge University Press.

Granhag, P.A. \& Strömwall, L.A. \& Jonsson, A.-C. (2003). Partners in crime: How liars in collusion betray themselves. Journal of Applied Social Psychology, 33, 848-868.

Hartwig, M., \& Bond, C. F. (2011). Why do lie-catchers fail? A lens model meta-analysis of human lie judgements. Psychological Bulletin, 137, 643-59. DOI: 10.1037/a0023589

Knieps, M., Granhag, P.A., \& Vrij, A. (2013a). Back to the future: Asking about mental images to discriminate between true and false intentions. Journal of Psychology Interdisciplinary \& Applied, 147, 619-640. DOI: 10.1080/00223980.2012.728542

Knieps, M., Granhag, P.A., \& Vrij, A. (2013b). Repeated visits to the future: Asking about mental images to discriminate between true and false intentions. International Journal of Advances in Psychology, 2, 93-102.

Mac Giolla, E. \& Granhag, P.A. (2013). Detecting false intent among small cells of suspects: Single vs. repeated interviews. Manuscript under preparation.

Malle, B.F., Moses, L.J. \& Baldwin, D.A. (2001). Intentions and intentionality. Foundations of social cognition. Cambridge; MA: The MIT Press.

Sheeran, P., Milne, S.E., Webb, T.L. \& Gollwitzer, P. M. (2005). Implementation intentions. In M. Conner \& P. Norman (Eds.), Predicting health behavior (2nd ed., pp. 276-323) Buckingham, UK: Open University Press.

Sooniste, T., Granhag, P.A., Knieps, M., \& Vrij, A. (2013). True and false intentions: Asking about the past to detect lies about the future. Psychology, Crime \& Law, 19, 673-685. 
Strömwall, L.A., Granhag, P.A., \& Jonsson, A.-C. (2003). Deception among pairs: "Let's say we had lunch and hope they will swallow it!". Psychology, Crime \& Law, 9, 209-124. DOI: $10.1080 / 1068316031000116238$

Van Mastrigt, S. B., \& Farrington, D. P. (2009). Co-offending, age, gender and crime type: Implications for criminal justice policy. British journal of criminology, 49, 552-573. Vrij, A \& Granhag, P.A. (2012). Eliciting cues to deception and truth: What matters are the questions asked. Journal of Applied Research in Memory \& Cognition, 2, 110-117. DOI: 10.1016/j.jarmac.2012.02.004

Vrij, A. (2008). Detecting lies and deceit: Pitfalls and opportunities. Chichester: John Wiley \& Sons.

Vrij, A., Granhag, P.A., Mann, S., \& Leal, S. (2011). Outsmarting the liars: Strategic and cognitive lie detection approaches. Current Directions in Psychological Science, 20, 2832.

Vrij, A., Jundi, S., Hope, L., Hillman, J., Gahr, E., Leal, S., Warmelink, L. Mann, S., Vernham, Z., \& Granhag, P. A. (2012). Collective interviewing of suspects. Journal of Applied Research in Memory and Cognition, 1, 41-44. DOI: 10.1016/j.jarmac.2011.12.002

Vrij, A., Leal, S., Granhag, P.A., Mann, S., Fisher, R., Hillman, J., \& Sperry, K. (2009) Outsmarting the liars: The benefit of asking unanticipated questions. Law and Human Behavior, 33, 159-166. DOI: 10.1007/s10979-008-9143-y

Vrij, A., Leal, S., Mann, S. A., \& Granhag, P. A. (2010). A comparison between lying about intentions and past activities: Verbal cues and detection accuracy. Applied Cognitive Psychology, 25, 212-218. DOI: 10.1002/acp.1665 